\title{
Reservoir forming conditions and exploration potential of Lower Paleozoic carbonate rocks in Gucheng area, Tarim Basin
}

\author{
Liu Zheng ${ }^{1, *}$, Yan Liping ${ }^{1}$,Sun Guoxin ${ }^{1}$,Ding Hansheng ${ }^{1}$, Li Yanjie ${ }^{1}$, \\ ${ }^{1}$ Exploration and Development Research Institute of Daqing Oilfield Co Ltd., Daqing 163712, China
}

\begin{abstract}
The Gucheng region is oil and gas accumulation area of Tarim Basin, dominated by beach controlled lithologic oil and gas reservoirs, which has superior oil and gas accumulation conditions and broad exploration prospects. The lower Paleozoic strata in the Gucheng region are the Carboniferous, Ordovician, and Cambrian systems from top to bottom. The Silurian, Devonian, and Permian systems are missing. The lower Ordovician - Cambrian are the main exploration target layers in the area. There are four reservoirs: the Ordovician group, the Yingshan group, the Penglaiba group and the Cambrian group in The Gucheng region, The upper part of the Yijianfang formation and Yingshan formation are limestone reservoir, which is a set of potential reservoir. The lower part of the Yingshan formation, the Penglaiba formation, and the Cambrian formation developed three sets of dolomite reservoirs. The distribution of oil and gas in Gucheng region was mainly found in Yijianfang formation, Yingshan formation, Penglaiba formation and Cambrian of the Ordovician. The Yingshan group and the Hanwu group were the main exploration target layers. Yingshan formation and Cambrian are the main exploration targets, and Yijianfang formation and Penglaiba formation of Ordovician can be used as the concurrent exploration targets. Gucheng region can form two major realistic exploration areas: dolomite reservoir of Ordovician and reef beach of Cambrian. The Ordovician dolomite reservoirs are mainly searched for the inner shoal of the platform edge high-energy facies belt, and the Cambrian system is mainly search for the high-energy reef beach far away from the platform edge facies belt in the north of cherchen fault.
\end{abstract}

\section{Introduction}

The marine sedimentary basins in China were mainly developed in the Paleozoic Era and contained abundant oil and gas resources [1-4]. However, the formation of marine carbonate reservoirs in China is early and the stratigraphic age is old [5-6]. The exploration target layer is deeply buried and multi-phase tectonic movements are superimposed. The rules of hydrocarbon accumulation and enrichment are very complicated, which affect the breakthrough in the oil and gas exploration of China's marine carbonate reservoirs. Tarim Basin is a superimposed basin [7]. With the continuous discovery of oil and gas in the Yingshan Formation and Cambrian dolomite in Tazhong and Tabei, it has become one of the largest oil and gas basins in China. The Gucheng Low Uplift is located in the central-southern part of the northern depression area of the Tarim Basin, adjacent to the East Uplift in the east, and adjacent to the Du Uplift in the west. (Figure 1). It is a large, wide, gentle nose-like structure dipping from north to west [8-9], with an area of about $6100 \mathrm{~km} 2$. At present, TJ13 well, TJ13-2 well, TJ13-3 well, and TJ13-4 well, which have been drilled in the three-dimensional area, have respectively obtained 260,000 cubic meters, 478,000 cubic meters, 1.0789 thousand cubic meters and 227,300

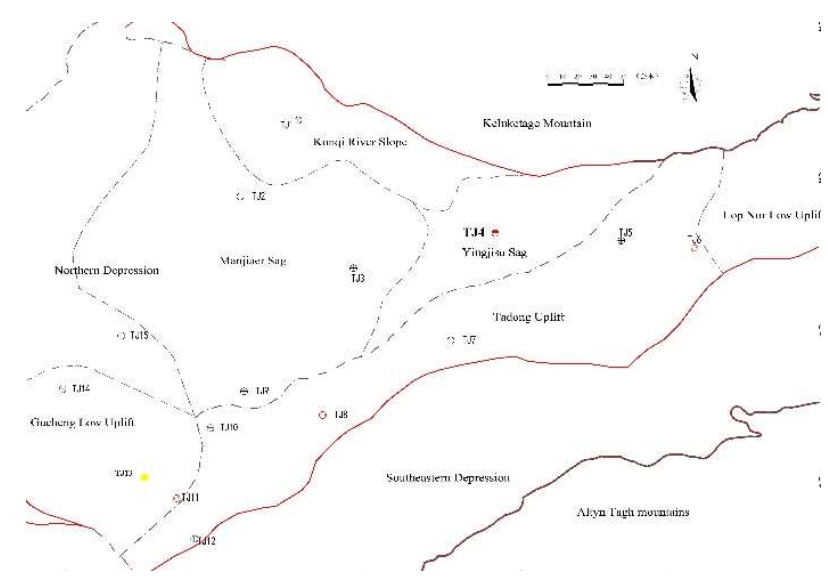

Fig. 1. Structural location map of the Gucheng area.

cubic meters of high-yield airflow in the Ordovician Eagle III. The Gucheng area has a favorable structural location, well-developed carbonate reservoirs and favorable accumulation conditions. It has the petroleum geological conditions for the formation of large-medium-sized oil and gas fields. It has large exploration potential and abundant resources. A number of research results have been obtained by researchers on the oil and gas accumulation conditions in the adjacent Tazhong area [10-14], but the current exploration level in the Gucheng

\footnotetext{
* Corresponding author: liuzheng3@petrochina.com
} 
area is very low, and there is no clear understanding of the oil and gas accumulation conditions and rules, which restricts the understanding of the oil and gas resource potential of the Gucheng area, and some problems remain to be resolved.

\section{Geological characteristics}

\subsection{Stratigraphic characteristics}

According to seismic and drilling data, the Paleozoic strata in the Gucheng area developed Cambrian, Ordovician and Carboniferous from bottom to top, and Devonian and Permian were absent. The thickness of the Lower Paleozoic is more than $5000 \mathrm{~m}$. The Silurian is only distributed at the northern tip of the rhinoplasty of Gucheng. The Cambrian, Ordovician and Carboniferous are basically distributed throughout the region. The Lower Ordovician-Cambrian is the main exploration target layer in this area.

\subsection{Structural features}

From the perspective of the tectonic evolution history of the Gucheng area, the Gucheng area has experienced Caledonian, Hercynian, Indosinian-Yanshanian, Himalayan and other tectonic movements. With slight adjustments, the late-active faults are mainly distributed near the Cherchen fault in the south. Therefore, since the Late Caledonian, the Gucheng area has been a long-term inherited large-scale nose structure with early formation and weak late tectonic activity and is well preserved (Figure 2). In addition, the Gucheng area is close to slopes and basins-favorable source rock development areas, which have favorable conditions, and are long-term oil and gas migration points. The barrier blocks and local structural traps in the Gucheng area, which are located in relatively high structural positions, are favorable areas for late natural gas accumulation.

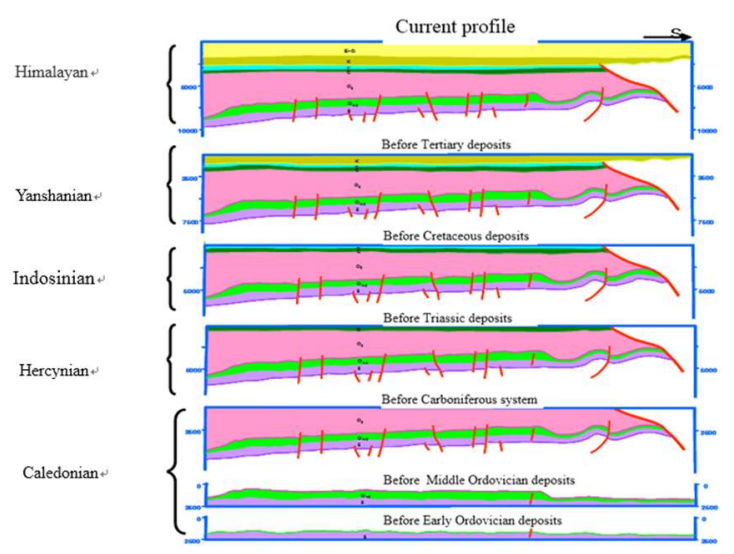

Fig. 2. Sectional diagram of structural development in Gucheng area

\subsection{Structural features}

Sedimentary facies control the nature of the reservoir and affect the enrichment of oil and gas [14]. Controlled by the rise and fall of sea level, the Lower Paleozoic Cambrian to Middle-Lower Ordovician water bodies in the Gucheng area experienced a process from the Cambrian water body becoming shallower to the Ordovician gradually becoming deeper, and it experienced a gentle slope $\rightarrow$ rim The evolution process of type platform $\rightarrow$ submerged platform, Cambrian-Early Ordovician, Gucheng area is a confined platform-semirestricted platform deposition, and the quasicontemporaneous dolomite formed under the control of the Cambrian confined sedimentary environment is relatively stable., And low-energy environment microcrystalline limestone, showing a restricted platform sedimentary environment with limited water flow and low energy. The Penglaiba Formation is a semi-limited platform, mainly composed of sprite sandstone limestone and oolitic limestone. Early Ordovician in the late-early Ordovician, the Gucheng platform was uplifted strongly due to the collision between the West Kunlun Island and the Tarim board [15]. The Yingshan Formation Yijianfang Formation developed platform marginal sandy shoal deposits, mainly brightly developed. Crystalline sand clastic limestone, microcrystalline limestone, medium-fine crystalline dolomite, the Upper Ordovician Tumuxuke Formation mainly develops bioclastic (including mud) limestone, micrite, microcrystalline limestone, and nodules Limestone, etc., reflect the low-energy environmental deposits of the submerged platform in relatively deep water.

\subsection{Reservoir characteristics}

Lower Ordovician-Cambrian reservoir lithology is mainly fine-medium crystalline dolomite. The core is parallel and the oblique bedding is developed (cracking along the bedding). The residual grain structure and phantom can be seen under the microscope, reflecting the high-energy grain beach facies which are formed by cloudification (Figure 4). The reservoir spaces are mainly of intercrystalline (dissolved) pores and caves, and the main type is porosity (Figure 3). Fractures are partially improved to form fracture-pore (cavity) reservoirs. The overall reservoir is characterized by "low porosity and ultra-low permeability", and the porosity and permeability have good correlation. The measured porosity of the core is mainly distributed between $1.8 \%$ and $5.0 \%$, and the permeability is between 0.01 and $10 \mathrm{mD}$.
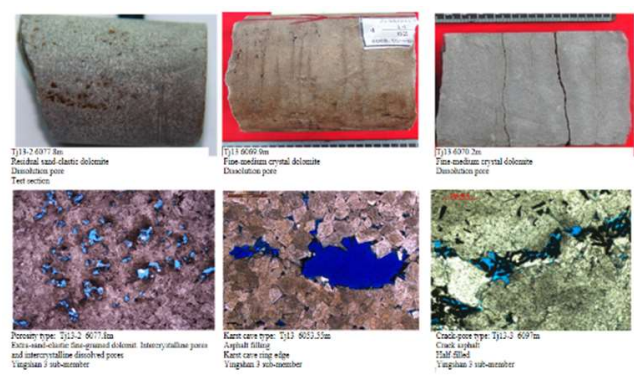

Fig. 3. Core slice in Gucheng area. 


\subsection{S Source-reservoir-seal combination}

The Gucheng area is bordered by the Manjiaer CambrianOrdovician Lower Paleozoic oil-generating depression in the north, which has relatively rich oil and gas sources [16-17]. The source rock is mainly composed of two sets of argillaceous rocks (mudstone and shale) and argillaceous limestone from the Cambrian to the MiddleLower Ordovician. The Lower Paleozoic source rock in the Manjiaer Sag of the Late Caledonian entered the peak of hydrocarbon generation and expulsion, and it was a condensate source kitchen [18-19]. The analysis of cuttings in TJ13-1 well and TJ13-2 well showed that the TOC of Ordovician hydrocarbon source is 0.03 to $0.81 \%$, averaging at $0.22 \%$, and the abundance of organic matter is low. The Cambrian-Ordovician source rocks in the Gucheng area are not developed, and the oil source comes from the Manjiaer sag on the east side.

The Gucheng area developed four sets of reservoirs, namely, Ordovician Yijianfang, Yingshan, Penglaiba and Cambrian. The upper part of the Yijianfang and Yingshan formations are limestone reservoirs, with micrite limestone and sandy limestone. There are three sets of dolomite reservoirs developed in the lower part of Yingshan Formation, Penglaiba Formation and Cambrian, with powdery, fine and medium-coarse crystal dolomites, among which fine-medium-coarse crystal dolomites form favorable reservoirs.

Three sets of reservoir-cap combinations developed in the Gucheng area. The thickness of the upper tight limestone caprock of the Yingsan Formation dolomite is $400-500 \mathrm{~m}$, the thickness of the upper dolomite caprock of the Penglaiba Formation is $100-180 \mathrm{~m}$, and the thickness of the caprock developed on the top of the Cambrian dolomite is $100-120 \mathrm{~m}$. Affected by the thickness and fracture of the caprock, the first set of reservoirs and caps has good oil and gas bearing capacity. The Upper Ordovician Queerchak Formation, which is several kilometers thick, is dominated by mudstone deposits, which can be used as a regional caprock, conducive to the preservation of oil and gas generated in the Lower Paleozoic (Figure 4).

\section{Oil and gas distribution characteristics and prediction of favorable areas}

Three sets of reservoir-cap combinations developed in the Gucheng area. The thickness of the upper tight limestone caprock of the Yingsan Formation dolomite is $400-500 \mathrm{~m}$, the thickness of the upper dolomite caprock of the Penglaiba Formation is $100-180 \mathrm{~m}$, and the thickness of the caprock developed on the top of the Cambrian dolomite is $100-120 \mathrm{~m}$. Affected by the thickness and fracture of the caprock, the first set of reservoirs and caps has good oil and gas bearing capacity. The Upper Ordovician Queerchak Formation, which is several kilometers thick, is dominated by mudstone deposits, which can be used as a regional caprock, conducive to the preservation of oil and gas generated in the Lower Paleozoic (Figure 4). The Gucheng area has a geological development history of early uplift, mid-

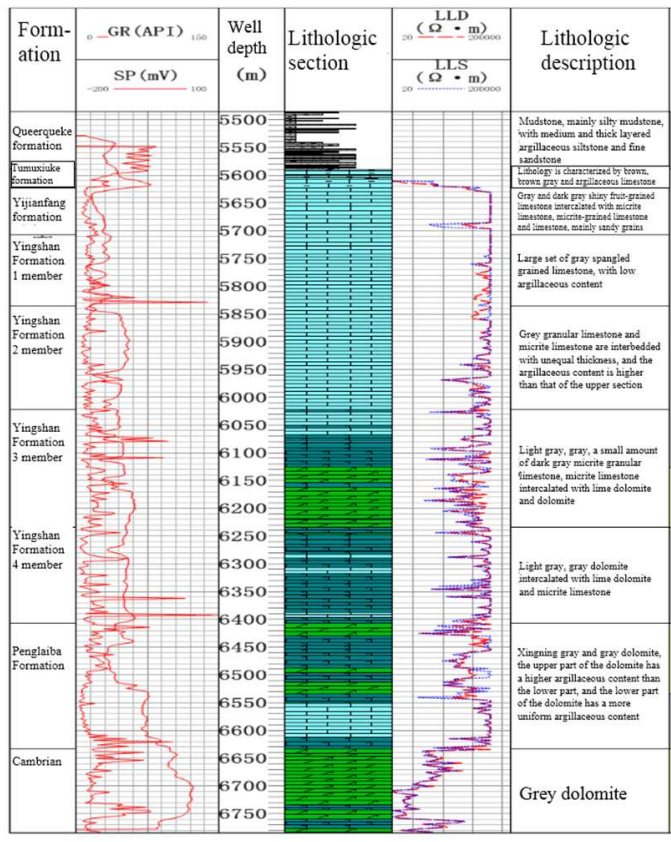

Fig. 4. Distribution map of reservoir-cap combinations in Gucheng area.

subsidence stereotypes, and late stability. It is more favorable for later preservation of oil and gas and is a favorable accumulation area for natural gas. At present, the oil and gas distribution in the Gucheng area is mainly found in the Yingshan Formation and Cambrian of the Ordovician. Among them, the Yingshan Formation has obtained industrial oil and gas discoveries, and the upper Cambrian reefs and banks have also seen good oil and gas shows. The Gucheng area has good oil and gas accumulation conditions. The effective reservoir-cap configuration relationship controls the distribution of oil and gas. The high-quality shoal facies reservoirs control the degree of oil and gas enrichment. Studies have shown that oil and gas are distributed in a quasi-layered large area in the horizontal direction, and by multiple stages of later reservoir transformation in the vertical direction, and are not controlled by structural heights and lows. The distribution and heterogeneity are obvious. The reservoir type should be a quasi-layered lithologic gas reservoir. On this basis, combined with the current drilling data, two realistic exploration areas can be identified in the Lower Paleozoic in Gucheng area: Ordovician dolomite reservoirs and Cambrian platform margin reef banks. Ordovician dolomite reservoirs are mainly used to search for intra-platform beaches in the high-energy facies zone dolomitized at the edge of the platform. The middle and lower parts of the Ordovician Yingshan Formation are favorable exploration targets. TJ13 well and TJ13-2 well in the dolomite reservoirs in the third member of the Ordovician Ying platform have obtained industrial oil and gas flow. The Penglaiba Formation in TJ13-1 well encountered dolomite, with good reservoir properties and well-developed fractures and cavities. TJ13-1 well obtained 3810 cubic meters of gas. Penglaiba formation can be used as the alternative target for exploration and exploration. The Cambrian platform margin belt runs through the north-south Gucheng-Lunnan of the Tarim Basin, with a length of $560 \mathrm{~km}$, a width of $15-90 \mathrm{~km}$, and 
an area of $23380 \mathrm{~km} 2$. The platform margin belt in the Gucheng area has a favorable exploration area of $1,400 \mathrm{~km} 2$, with large-scale reef-shoal traps developed. The biological reef shoals in the high-energy facies belt in the platform margin can form more favorable reservoirs, which are close to the oil source. This is conducive to the formation of large-scale lithologic oil and gas reservoirs. The Cambrian platform margin zone encountered in TJ11 well is a collapsed front facies, with fracture-cavity reservoirs and breccia-like asphalt. The main reason for the failure was that it was close to the southern fault, and the later preservation conditions were not good, and the oil reservoir was destroyed; to the south, it was severely affected by the Cherchen fault. The Cambrian platform margin belt in the north developed four stages of reefbanks as shown on the seismic profile, extending from the platform margin to the east, away from the Cherchen fault on the south margin [20], the conditions for oil and gas accumulation are favorable. The Cambrian dolomitized high-energy reef shoal reservoir of $\mathrm{Ct} 1$ well has resulted in good oil and gas show, and the highest total hydrocarbon gas surveyed is $83.7 \%$. The northern platform margin belt in the Gucheng area is the main target for future Cambrian platform margin exploration.

\section{Conclusion}

(1) The Lower Paleozoic strata in the Gucheng area are composed of Carboniferous, Ordovician and Cambrian from top to bottom, and Silurian, Devonian and Permian are missing. The Lower Ordovician-Cambrian is the main exploration target of this area.

(2) There are four sets of reservoirs in Gucheng Low Uplift, that is, Ordovician Yijianfang Formation, Yingshan Formation, Penglaiba Formation and Cambrian. The upper part of Yijianfang Formation and Yingshan Formation are limestone reservoirs, which are a set of potential reservoirs. There are three sets of dolomite reservoirs developed in the lower part of Yingshan Formation, Penglaiba Formation and Cambrian.

(3) The oil and gas distribution in the Gucheng area is mainly found in the Ordovician Yijianfang Formation, Yingshan Formation, Penglaiba Formation and Cambrian. Yingshan Formation and Cambrian are the main exploration targets, and Ordovician Yijianfang Formation The Penglaiba Formation can be used as an alternative exploration target.

(4) The Lower Paleozoic in the Gucheng area can form two realistic exploration areas: Ordovician dolomite reservoirs and Cambrian reef banks. The Ordovician dolomite reservoirs are mainly looking for intra-platform beaches in the platform margin high-energy facies belt, and the Cambrian is mainly looking for high-energy reefs and beach bodies away from the platform margin facies belt in the northern part of the Cherchen fault.

\section{References}

1. Zhu Guangyou, Yang Haijun, Zhu Yongfeng, et al. Study on hydrocarbon geological characteristics and accumulation of carbonate rocks in Hatang area of
Tarim Basin [J]. Acta petrologica sinica, 27 (3): 827842 (2011).

2. Zhang Shuichang, Zhang Baomin, Li Benliang, et al. History of oil and gas accumulation in marine basins across major tectonic periods in China: taking Tarim Basin as an example [J]. Petroleum Exploration and Development, 38 (1): 1-15 (2011).

3. Luo chunshu, Yang Haijun, Li jianghai, et al. Characteristics of Ordovician high-quality reservoirs and fault control in central Tarim basin [J]. Petroleum exploration and development, 38 (6): 716-724 (2011).

4. Zhao Wenzhi, Shen Anjiang, $\mathrm{Hu}$ Suyun, et al. Geological conditions and distribution characteristics of large-scale development of carbonate reservoirs in China $[\mathrm{J}]$. Petroleum Exploration and Development, 39 (1): 1-12 (2012).

5. Zhu Guangyou, Zhang Shuichang. Conditions of deep oil and gas accumulation and exploration potential in China [J]. Acta petrolei sinica, 30 (6): 793-800 (2012).

6. Zheng Herong, Wu Mao, Wu Xingwei, et al. Oil and gas exploration prospect of lower Paleozoic dolomite reservoir in Tarim Basin [J]. Acta petrolei sinica, 28 (2): 1-8 (2007).

7. Tian Lei, Cui Haifeng, Liu Jun, et al. [J]. Paleogeography and Sedimentary Evolution of Early and Middle Cambrian in Tarim Basin [J]. Petroleum and Natural Gas Geology, 39 (5): 1011-1021 (2018).

8. Wang Zhaoming, Yang Haijun, Qi Yingmin, et al. Major breakthroughs in Ordovician natural gas exploration in Gucheng area of Tarim Basin and its enlightenment [J]. Natural Gas Industry, 34 (1): 1-9 (2014).

9. Liu Yanting, Fu Heng, Kelvin Chen, et al. Sequence stratigraphic characteristics of Cambrian in BachuTazhong area of Tarim Basin [J]. Lithologic Reservoir, 22 (2): 48-53 (2002).

10. Yang Haijun, Han Jianfa, Chen Lixin, et al. Characteristics and models of hydrocarbon accumulation of marine carbonate rocks in Tazhong Middle Uplift. Petroleum and Natural Gas Geology, 28(6):784-790 (2007).

11. Xiao Zhongyao, Lu Yuhong, Sang Hong, et al. A typical CAMBRIAN reservoir: genetic analysis of well Tazhong 62 in Tarim Basin [J]. Geochemistry, 34 (2): 155-160 (2005).

12. Hua Xiaoli, Lu Xiuxiang, Huaqiao. Distribution law and reservoir forming conditions of fractured-vuggy carbonate rocks: a case study of Yingshan Formation in the east of Tazhong North Slope [J]. Journal of Modern Geology, 27 (2): 346-355 (2013).

13. Zhou Xinyuan, Wang Zhaoming, Yang Haijun, et al. The fifth exploration example of marine oil and gas fields in China-Exploration and discovery of Ordovician large condensate gas fields in Tazhong [J]. Marine Oil and Gas Geology, 11 (1): 45-51 (2006).

14. Yang jun, Jiang zhenxue, Xiang caifu, et al. hydrocarbon characteristics and genetic mechanism 
of carbonate rocks in Tazhong 83- Tazhong 16 well area of Tarim basin [j]. petroleum and natural gas geology, 33 (1): 101-109 (2012).

15. Li Minggang, Pang Xiongting, Ma Zhongzhen, et al. Analysis of main controlling factors of hydrocarbon accumulation in Wuerxun-Beier Sag [J]. Daqing Petroleum Geology and Development, 26 (5): 1-4 (2007).

16. Han Jianfa, Zhang Haizu, Yu Hongfeng, et al. Reservoir-forming characteristics and exploration of marine carbonate large condensate gas field in Tazhong uplift [J]. Acta Petrologica Sinica, 28 (3): 769-780 (2012).

17. Liu keqi, Jin Zhijun, Lu xiuxiang, et al. hydrocarbon accumulation of Ordovician carbonate rocks in Tazhong low uplift of Tarim basin [J]. Petroleum Experimental Geology, 26 (6): 531-536 (2004).

18. Yi Shiwei, Du Jinhu, Yang Haijun, et al. Controlling Factors of Lower Paleozoic Reservoir Formation in Tarim Basin and Exploration Ideas [J]. China Petroleum Exploration, 3 (1): 1-7 (2012).

19. Qian Ling, Li Jianghai, Lu Yuhong, et al. Difference analysis of oil and gas accumulation between Gucheng 4 well and Luoxi 1 well in Tadong area [J]. Natural Gas Geoscience, 22 (4): 628-634 (2012). 